\title{
Pengembangan E-Learning Menggunakan Schoology Berbasis Guided Discovery Learning pada Materi Laju Reaksi Kelas XI SMA/MA
}

\section{Development of E-Learning Using Schoology Based on Guided Discovery Learning on Reaction Rate Material for Class XI SMA/MA}

\author{
H Habibah ${ }^{1 *}$, and Suryelita ${ }^{1}$ \\ ${ }^{1}$ Pendidikan Kimia, Universitas Negeri Padang, Jl. Prof. Dr. Hamka, Air Tawar Barat, \\ Padang Utara, Sumatera Barat, Indonesia. 25171 \\ *hananhabibah05@gmail.com
}

\section{ARTICLE INFO}

Received on:

23 December 2021

Revised till:

24 January 2022

Accepted on:

25 January 2022

Publisher version published on:

15 February 2022

\begin{abstract}
The Covid-19 pandemic has an impact on the education sector, so technology is needed that can support the learning process, one of which is the use of e-learning. This research aims to develop and determine the validity of e-learning using Schoology based on Guided Discovery Learning (GDL) on the reaction rate material for class XI SMA/MA. The type of research used is development research using the plomp development model. The stages in the plomp model are limited to expert review and one to one evaluation, namely the prototype III. The expert review was carried out by six material expert validators and three media expert validators, while the one to one evaluation was carried out by three students with different abilities. The results of the assessment on each validity questionnaire were processed using the Aiken's $V$ formula. Based on the research results, e-learning using Schoology based on GDL model on the reaction rate material can be considered as valid. Further research is needed to determine the practicality and effectiveness of e-learning using Schoology based on GDL model.
\end{abstract}

\section{KEYWORDS}

E-learning, Guided Discovery Learning, Plomp, Reaction Rate, Schoology

\begin{abstract}
ABSTRAK
Pandemi Covid-19 berdampak terhadap bidang pendidikan sehingga dibutuhkan teknologi yang dapat menunjang proses pembelajaran, salah satunya dengan penggunaan e-learning. Tujuan penelitian ini ialah untuk mengembangkan dan menentukan kevalidan e-learning menggunakan Schoology berbasis Guided Discovery Learning (GDL) pada materi laju reaksi kelas XI SMA/MA. Jenis penelitian yang digunakan adalah development research menggunakan model pengembangan plomp. Tahapan pada model plomp dibatasi sampai penilaian expert review dan one to one evaluation yakni pada tahap prototipe III. Expert review dilakukan oleh enam validator ahli materi dan tiga validator ahli media, sedangkan one to one evaluation dilakukan oleh tiga orang peserta didik yang memiliki kemampuan yang berbeda. Hasil penilaian pada setiap angket validitas diolah menggunakan rumus Aiken's V. Berdasarkan hasil penelitian, e-learning menggunakan Schoology berbasis GDL pada materi laju reaksi telah valid. Diperlukan penelitian lanjutan untuk mengetahui praktikalitas dan efektivitas dari e-learning menggunakan Schoology berbasis GDL yang dikembangkan.
\end{abstract}

KATA KUNCI

E-learning, Guided Discovery Learning, Laju Reaksi, Plomp, Schoology 


\section{PENDAHULUAN}

Pandemi Covid-19 memberi dampak terhadap bidang pendidikan di Indonesia terutama dalam proses pembelajaran ${ }^{[1]}$. Pemerintah memberi kebijakan agar pembelajaran dapat dilakukan secara luring ataupun daring sesuai dengan ketentuan yang telah dijelaskan pada Surat Keputusan Bersama (SKB) Empat Menteri ${ }^{[2]}$. Pembelajaran yang dilakukan secara daring dari rumah masing-masing tentu memerlukan bantuan teknologi ${ }^{[3]}$.

Salah satu pemanfaatan teknologi dalam bidang pendidikan adalah penggunaan e-learning yang merupakan sarana penyampaian pembelajaran menggunakan jaringan internet $\mathrm{t}^{[4-5]}$. E-learning yang biasa digunakan berupa media sosial seperti WhatsApp, YouTube dan Learning Management System (LMS) seperti Edmodo, Schoology, Moodle, dll. E-learning yang dirancang dengan benar dapat secara efektif dan efisien membantu peserta didik untuk memiliki pengetahuan faktual, teoritis, logis, dan prosedural ${ }^{[6]}$. Dengan demikian e-learning dapat memudahkan kegiatan pembelajaran daring terlaksana dengan baik termasuk dalam pembelajaran kimia.

Materi kimia yang dipelajari di SMA/MA salah satunya adalah laju reaksi. Karakteristik yang terdapat pada materi laju reaksi memuat konsep abstrak, hitungan matematis, grafik dan melibatkan multirepresentasi (makroskopis, sub-mikroskopis dan simbolik) ${ }^{[7]}$. Kurangnya pemahaman terhadap karakteristik materi laju reaksi tersebut menyebabkan peserta didik kesulitan dalam mempelajari materi laju reaksi ${ }^{[8]}$. Hal ini dapat dibuktikan berdasarkan angket yang diberikan kepada 31 peserta didik di MAN 1 Kota Bukittinggi mengenai permasalahan yang timbul selama pembelajaran daring pada materi laju reaksi menunjukkan bahwa $65 \%$ tidak menyukai materi laju reaksi karena materi tersebut sulit dipahami.

Kesulitan dalam mempelajari materi laju reaksi berdasarkan observasi yang dilakukan disebabkan beberapa faktor yaitu, proses pembelajaran hanya terpusat kepada pemberian materi dan tugas. Fokus peserta didik terganggu karena platform digital yang digunakan dalam proses pembelajaran berbedabeda seperti, e-learning madrasah, WhatsApp dan Google Classroom. Menurut Hidayati (2021) komunikasi antara guru dan peserta didik kurang efektif pada e-learning madrasah, karena itulah guru menggunakan media lain yang mudah diakses dan digunakan seperti WhatsApp ${ }^{[9]}$. Aplikasi yang rumit juga membuat guru kesulitan dalam menggunakan beberapa fitur yang terdapat pada e-learning madrasah $^{[10]}$. Untuk itu dibutuhkan e-learning yang memiliki fitur yang memadai serta penggunaannya yang mudah dipahami. Salah satunya adalah e-learning Schoology.

Ferdianto dan Dwiniasih (2019) menjelaskan bahwa Schoology adalah LMS berupa platform media sosial yang memiliki fitur-fitur lengkap dan dapat terjadinya kolaborasi antara guru dengan guru lain, siswa, serta orang tua ${ }^{[11]}$. Adanya ruang diskusi kelas dan ruang diskusi kelompok memudahkan terjadinya interaksi. Selain itu guru dapat mengolah hasil belajar mengajar secara otomatis melalui sistemnya $^{[12]}$. Penggunaan Schoology lebih mudah dipahami (user friendly) ${ }^{[13]}$. Kelebihan yang dimiliki oleh Schoology adalah terdapatnya fasilitas analytic yang berfungsi untuk melihat semua kegiatan yang dilakukan peserta didik ${ }^{[12]}$.

Untuk mendapatkan penggunaan sistem e-learning Schoology yang baik diperlukan perancangan yang baik pula ${ }^{[14]}$. Dibutuhkan proses pembelajaran yang terstruktur dalam mewujudkan keberhasilan pembelajaran kimia sesuai tuntutan kurikulum 2013 yaitu dengan menggunakan pendekatan saintifik ${ }^{[15]}$. Keberhasilan pendekatan saintifik dalam meningkatkan kualitas pembelajaran kimia dapat dilakukan dengan menggunakan model pembelajaran ${ }^{[16]}$. Model pembelajaran yang dapat diterapkan dan dikolaborasikan ke dalam e-learning, salah satunya adalah model guided discovery learning (GDL).

GDL adalah model pembelajaran yang diberikan guru berupa bimbingan baik itu petunjuk, arahan, atau umpan balik. Model guided discovery learning dapat menuntun peserta didik untuk aktif menemukan konsep dengan bimbingan guru $^{[17]}$. Tahapan dalam model GDL yaitu: (1) Motivasi dan presentasi masalah; (2) Pemilihan kegiatan pembelajaran; (3) Pengumpulan data; (4) Pengolahan data; (5) Penutup. Dari tahapan tersebut, guru dapat membimbing peserta didik untuk terus belajar agar lebih termotivasi ${ }^{188}$.

Model GDL atau disebut juga dengan penemuan terbimbing lebih efektif dapat membantu peserta didik dalam proses belajar dibandingkan dengan penemuan murni ${ }^{[19]}$. Hal ini dikarenakan menemukan konsep tanpa bimbingan dari guru membutuhkan waktu yang relatif lama. Terdapat kemungkinan terjadi kesalahan pemahaman dari umpan balik yang diberikan peserta didik ${ }^{[20]}$.

Penelitian relevan terkait pengembangan e-learning berbasis Schoology telah dilakukan oleh Putri et. al. (2014) ${ }^{[21]}$. Nilai rata-rata setelah menggunakan Schoology pada pembelajaran IPA lebih tinggi dibandingkan sebelum menggunakan Schoology. Penelitian yang telah dilakukan Huurun'ien (2017) ${ }^{[2]}$ menjelaskan bahwa e-learning berbasis Schoology yang digunakan dengan model discovery learning pada pembelajaran sistem komputer lebih efektif meningkatkan hasil belajar peserta didik.

\section{METODE}

Jenis penelitian ialah pengembangan atau development research menggunakan model plomp. Terdapat tiga tahapan dalam pengembangan model plomp yakni tahap penelitian pendahuluan (preliminary research), tahap pengembangan prototipe (prototyping phase), dan tahap penilaian (assessment phase). Penelitian ini dibatasi sampai tahapan prototipe III yaitu hingga penilaian ahli (expert review) dan uji coba satu-satu (one to one evaluation). 
Pada tahap penelitian pendahuluan dilakukan dengan kegiatan (1) analisis kebutuhan, yaitu menganalisis dan mengumpulkan informasi, mendefinisikan masalah, serta merencanakan kelanjutan penelitian; (2) analisis konteks, yaitu dengan menganalisis kompetensi dasar untuk merumuskan tujuan pembelajaran yang ingin dicapai sesuai tuntutan kurikulum 2013; (3) studi literatur yang didapatkan dari kumpulan berbagai sumber baik itu buku, jurnal, artikel, maupun referensi dari internet berkenaan dengan pemecahan masalah dalam kegiatan penelitian yang dilakukan; serta (4) pengembangan kerangka konseptual. Yang dikembangkan dengan mengacu pada semua gagasan yang mendasari terbentuknya produk ${ }^{[23]}$.

Tahapan pengembangan prototipe dilakukan dengan merancang kerangka acuan dan menyusun prototipe. Tahapan ini dilakukan dalam beberapa siklus yang terdiri dari perancangan prototipe, evaluasi formatif, dan revisi yang dilakukan berulang kali. Pada tahap awal pengembangan dilakukan dengan merancang dan mendesain produk dalam bentuk story board. Hasil rancangan yang dibuat bertujuan untuk menghasilkan prototipe I.

Hasil dari tahapan prototipe I yang telah dirancang selanjutnya direalisasikan untuk menghasilkan produk berupa e-learning menggunakan Schoology berbasis GDL pada materi laju reaksi. Hasil prototipe I yang selesai dibuat kemudian dilakukan evaluasi formatif melalui evaluasi diri sendiri (self evaluation). Komponen yang harus ada dapat dievaluasi menggunakan daftar periksa yang bertujuan untuk mengetahui kelengkapan dari rancangan yang telah dibuat sebelumnya. Setelah melakukan self evaluation maka dihasilkanlah prototipe II.

Prototipe II yang dihasilkan kemudian dilakukan evaluasi formatif berupa tinjauan ahli (expert review) oleh enam validator ahli materi yang terdiri dari dan tiga validator ahli media serta evaluasi perorangan (one to one evaluation) oleh tiga orang peserta didik. Validator ahli materi terdiri dari tiga orang dosen kimia FMIPA UNP dan tiga orang guru kimia. Sedangkan validator ahli media dilakukan oleh tiga orang dosen teknik informatika FT UNP.

Instrumen yang digunakan ialah angket validitas konten, konstruk, dan ahli media menggunakan skala likert untuk uji validasi. Item yang dinilai dalam validitas konten berhubungan dengan state-of-the-art pengetahuan yaitu berdasarkan dengan teori yang memadai ${ }^{[24]}$. State-of-the-art pengetahuan dalam penelitian ini mencakup LMS Schoology, guided discovery learning, dan materi laju reaksi. Sedangkan item yang dinilai dalam validitas konstruk berhubungan dengan keterkaitan komponen antara satu dengan yang lainnya secara konsisten ${ }^{[24]}$. Pada validasi ahli media terdapat tiga aspek yang dinilai yaitu aspek tampilan, pemograman dan pemanfaatan.

Data yang diperoleh dari hasil validasi diolah menggunakan formula Aiken's $\mathrm{V}^{[25]}$ yang ditunjukkan pada Persamaan 1 dan Persamaan 2. Dimana, $V$ adalah indeks kesepakatan; $s$ adalah skor yang ditetapkan; $r$ adalah skor kategori pilihan ahli; lo adalah skor terendah dalam penskoran; $c$ adalah banyaknya kategori yang dipilih ahli; dan $n$ adalah jumlah ahli.

$$
\begin{aligned}
& \mathrm{V}=\frac{\sum s}{n(c-1)} \ldots \text { Persamaan } 1 \\
& s=r-I o \ldots \text { Persamaan } 2
\end{aligned}
$$

Rentang indeks $V$ adalah 0 hingga 1 . Indeks $V$ yang diperoleh dari hasil perhitungan dapat diterima kevalidannya jika memenuhi nilai minimum kevalidan berdasarkan koefisien validitas pada tabel yang diberikan Aiken ${ }^{[25]}$.

Tahapan selanjutnya setelah dilakukannya evaluasi formatif adalah tahapan one to one evaluation. One to one evaluation dilakukan terhadap 3 orang peserta didik yang memiliki tingkat kemampuan yang berbeda-beda (tinggi, sedang, rendah). Tahapan ini bertujuan untuk mengetahui penilaian peserta didik terhadap produk dengan pemberian saran yang dilakukan pada lembar angket one to one evaluation.

\section{HASIL DAN DISKUSI}

\subsection{Tahapan Penelitian Pendahuluan}

\subsubsection{Analisis kebutuhan}

Tahap analisis kebutuhan dilakukan dengan penyebaran angket kepada guru kimia dan peserta didik kelas XI di MAN 1 Kota Bukittinggi. Hasil analisis angket yang diperoleh yakni berbedabedanya platform yang digunakan dalam proses pembelajaran. Model pembelajaran sesuai dengan kurikulum 2013 belum terlaksana dalam proses pembelajaran daring. Bahan ajar yang tersedia juga belum dilengkapi dengan praktikum yang dapat dilakukan secara mandiri. Hal tersebut membuat peserta didik mengalami kesulitan untuk memahami materi laju reaksi. Berdasarkan hasil dari analisis kebutuhan, maka dikembangkan konten pembelajaran berupa e-learning menggunakan Schoology berbasis GDL pada materi laju reaksi.

\subsubsection{Analisis konteks}

Analisis konteks didapatkan dengan menganalisis kemampuan peserta didik yang harus dikuasai dalam proses pembelajaran sesuai dengan kurikulum. Berdasarkan analisis silabus pada kurikulum 2013 revisi 2018 yang telah dilakukan, didapatkan kompetensi dasar yang diturunkan menjadi indikator pencapaian kompetensi yang dapat dilihat pada Tabel 1. Indikator pencapaian kompetensi yang telah diperoleh dijadikan sebagai acuan untuk merumuskan tujuan pembelajaran.

\subsubsection{Studi literatur}

Hasil yang diperoleh berdasarkan studi literatur adalah pembelajaran daring menjadi solusi dalam menjalankan pendidikan di masa pandemi ${ }^{[3]}$. Salah satu yang dapat mendukung pembelajaran daring terlaksana dengan baik adalah penggunaan e-learning[26]. Menurut Hidayati (2021) 
Tabel 1. KD dan IPK Materi Laju Reaksi.

\begin{tabular}{|c|c|}
\hline Kompetensi Dasar (KD) & Indikator Pencapaian Kompetensi (IPK) \\
\hline $\begin{array}{l}\text { 3.6 Menjelaskan faktor-faktor } \\
\text { yang mempengaruhi laju reaksi } \\
\text { menggunakan teori tumbukan }\end{array}$ & $\begin{array}{l}\text { 3.6.1 Menjelaskan faktor-faktor yang mempengaruhi laju reaksi } \\
\text { berdasarkan teori tumbukan. } \\
\text { 3.6.2 Menentukan kecepatan laju reaksi berdasarkan contoh yang } \\
\text { diberikan }\end{array}$ \\
\hline $\begin{array}{l}\text { 3.7 Menentukan orde reaksi dan } \\
\text { tetapan laju reaksi berdasarkan } \\
\text { data hasil percobaan }\end{array}$ & $\begin{array}{l}\text { 3.7.1 Menentukan orde reaksi berdasarkan data hasil percobaan } \\
\text { 3.7.2 Menentukan tetapan laju reaksi berdasarkan data hasil } \\
\text { percobaan }\end{array}$ \\
\hline $\begin{array}{l}\text { 4.6 Menyajikan hasil penelusuran } \\
\text { informasi cara-cara pengaturan } \\
\text { dan penyimpangan bahan untuk } \\
\text { mencegah perubahan fisik dan } \\
\text { kimia yang tidak terkendali }\end{array}$ & $\begin{array}{l}\text { 4.6.1 Menyajikan hasil penelusuran mengenai cara-cara mengatur } \\
\text { bahan untuk mencegah perubahan fisika dan kimia yang tidak } \\
\text { terkendali } \\
\text { 4.6.2 Menyajikan hasil penelusuran mengenai penyimpanan bahan } \\
\text { untuk mencegah perubahan fisika dan kimia yang tidak terkendali }\end{array}$ \\
\hline $\begin{array}{l}4.7 \text { Merancang, melakukan, dan } \\
\text { menyimpulkan serta menyajikan } \\
\text { hasil percobaan faktor-faktor yang } \\
\text { mempengaruhi laju reaksi dan orde } \\
\text { reaksi }\end{array}$ & $\begin{array}{l}\text { 4.7.1 Merancang percobaan sederhana mengenai faktor-faktor yang } \\
\text { mempengaruhi laju reaksi } \\
\text { 4.7.2 Melakukan percobaan mengenai faktor-faktor yang } \\
\text { mempengaruhi laju reaksi } \\
\text { 4.7.3 Menyimpulkan hasil percobaan mengenai faktor-faktor yang } \\
\text { mempengaruhi laju reaksi } \\
\text { 4.7.4 Menyajikan hasil percobaan mengenai faktor-faktor yang } \\
\text { mempengaruhi laju reaksi }\end{array}$ \\
\hline
\end{tabular}

penggunaan e-learning madrasah yang tersedia belum mendukung proses pembelajaran daring sepenuhnya. Guru kesulitan dalam menggunakan beberapa fitur yang terdapat pada e-learning madrasah dan belum tersedianya fitur ruang diskusi kelompok. Sehingga guru memilih WhatsApp sebagai sarana utama penyampaian pembelajaran daring yang mudah digunakan ${ }^{[9]}$.

Sehingga dibutuhkan e-learning yang memiliki fitur yang memadai serta penggunaannya yang lebih sederhana dan user friendly salah satunya adalah Schoology ${ }^{[13]}$. Menurut Isfaraini dkk., (2016) penggunaan e-learning berbasis Schoology efektif dapat meningkatkan hasil belajar peserta didik. Diperlukan model pembelajaran yang dapat dikolaborasikan ke dalam e-learning berbasis Schoology yaitu model guided discovery learning. Kersh dan Wittrock (1962) dalam Smitha (2012) ${ }^{[18]}$ mengemukakan bahwa model guided discovery (penemuan terbimbing) dapat memotivasi peserta didik untuk dapat terlibat aktif menemukan konsep sesuai dengan tujuan pembelajaran.

\subsubsection{Pengembangan kerangka konseptual}

Hasil dari pengembangan kerangka konseptual dibuat dalam bentuk bagan memuat permasalahan yang ditemukan hingga solusi yang diberikan. Pengembangan kerangka konseptual dapat dilihat pada Gambar 1. Permasalahan yang diperoleh berdasarkan analisis kebutuhan dan konteks serta studi literatur yakni adanya kesulitan dalam penggunaan e-learning madrasah dan materi laju reaksi yang sulit dipahami karena belum menggunakan model pembelajaran. Permasalahan tersebut diatasi dengan pengembangan e-learning menggunakan Schoology berbasis GDL pada materi laju reaksi.
Fitur pada Schoology dimanfaatkan dan dikombinasikan dengan model GDL agar membantu pembelajaran daring terlaksana dengan baik. Fitur tersebut memuat fasilitas kelas dan kelompok, video, audio, gambar, teks, kuis, fasilitas absensi, ruang diskusi, buku penilaian, dll. Model GDL digunakan untuk memudahkan peserta didik secara mandiri menemukan konsep pada materi laju reaksi dengan bimbingan yang diberikan guru. Produk dikembangkan dengan menggunakan model plomp dan dianalisis menggunakan uji validasi untuk menentukan kevalidan dari produk yang dikembangkan.

\subsection{Tahapan pengembangan}

\subsubsection{Prototipe I}

Hasil rancangan berupa story board yang dibuat bertujuan untuk menghasilkan prototipe I. Rancangan yang dihasilkan memuat gambaran dari beberapa komponen pada tampilan awal courses (kelas) dan groups (kelompok).

Tampilan courses terdiri dari berbagai fitur-fitur Schoology yakni berupa: 1) material yang digunakan untuk memasukkan berbagai bahan ajar yang dibutuhkan, diantaranya petunjuk penggunaan, KI, $\mathrm{KD}$, IPK, tujuan pembelajaran, peta konsep, lembar kegiatan,linkZoomdandaftarpustaka.Lembarkegiatan mencakup 5 tahapan dari guided discovery learningyang memuat penjelasan dari materi laju reaksi berupa teks, gambar, video, pertanyaan menuntun menggunakan fitur assessment, kesimpulan menggunakan fitur kolom diskusi dan tugas yang diberikan menggunakan fitur assignment. 2) Update, digunakan untuk menampilkan setiap informasi baru baik yang dilakukan guru maupun peserta didik. 3) Grade book, digunakan untuk 


\section{Pengembangan Kerangka Konseptual pada Tahap Pendahuluan dari Proses Pengembangan e-Learning Menggunakan Schoology Berbasis Guided Discovery Learning pada Materi Laju Reaksi Kelas XI SMA/MA}

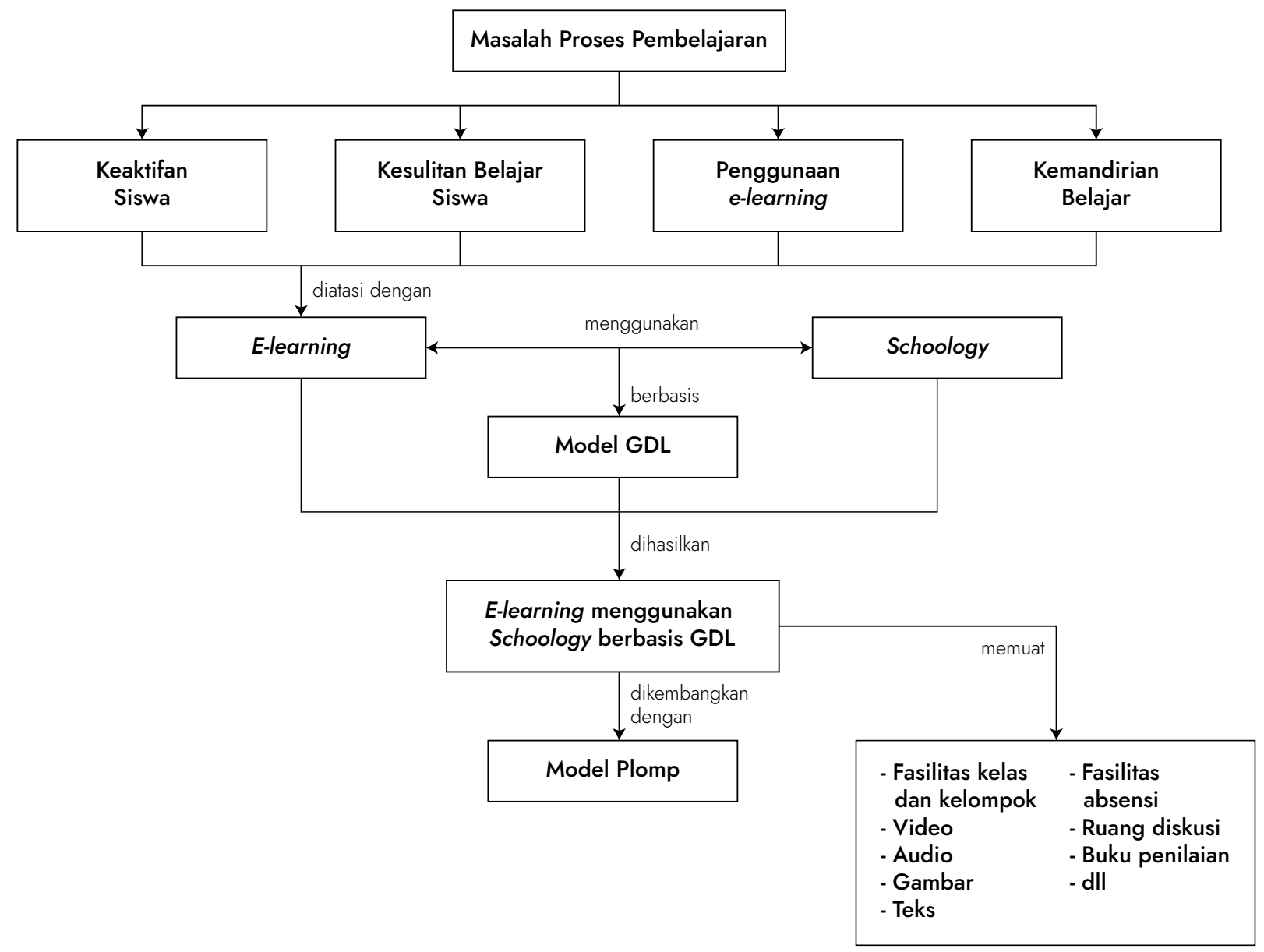

Gambar 1. Kerangka Konseptual.

menampilkan nilai peserta didik secara otomatis ${ }^{[27]}$. 4) Grade setup, digunakan untuk pengaturan kelas. 5) Badges digunakan untuk memberikan penghargaan kepada peserta didik terhadap hasil pembelajarannya. 6) Attendance digunakan untuk mencatat daftar hadir peserta didik. 7) Members untuk menampilkan jumlah peserta didik yang bergabung di dalam kelas ${ }^{[28]}$. Tampilan awal courses dapat dilihat pada Gambar 2.

Tampilan groups digunakan untuk membuat kelompok belajar. Pengumpulan dan pengolahan data dari lembar kegiatan didiskusikan di dalam forum diskusi. Hasil diskusi kelompok kemudian dimasukkan pada lembar kegiatan kelas yang telah disediakan.

\subsubsection{Prototipe II}

Hasil prototipe I yang telah selesai dibuat kemudian dilakukan evaluasi formatif melalui evaluasi diri sendiri (self evaluation). Komponen yang harus ada dapat dievaluasi menggunakan daftar periksa (check list) yang bertujuan untuk mengetahui kelengkapan dari rancangan yang telah dibuat sebelumnya. Pada penelitian ini dilakukan perbaikan pada gambar profil course agar tampilan lebih menarik dan melakukan perbaikan pada soal-soal di lembar kegiatan agar pertanyaan ditampilkan satu persatu untuk menuntun peserta didik menemukan konsep.

\subsubsection{Prototipe III}

Prototipe II yang dihasilkan kemudian dilakukan evaluasi berupa tinjauan ahli (expert review) oleh enam validator ahli materi dan tiga validator ahli media serta evaluasi perorangan (one to one evaluation) untuk mendapatkan produk pengembangan yang valid. 


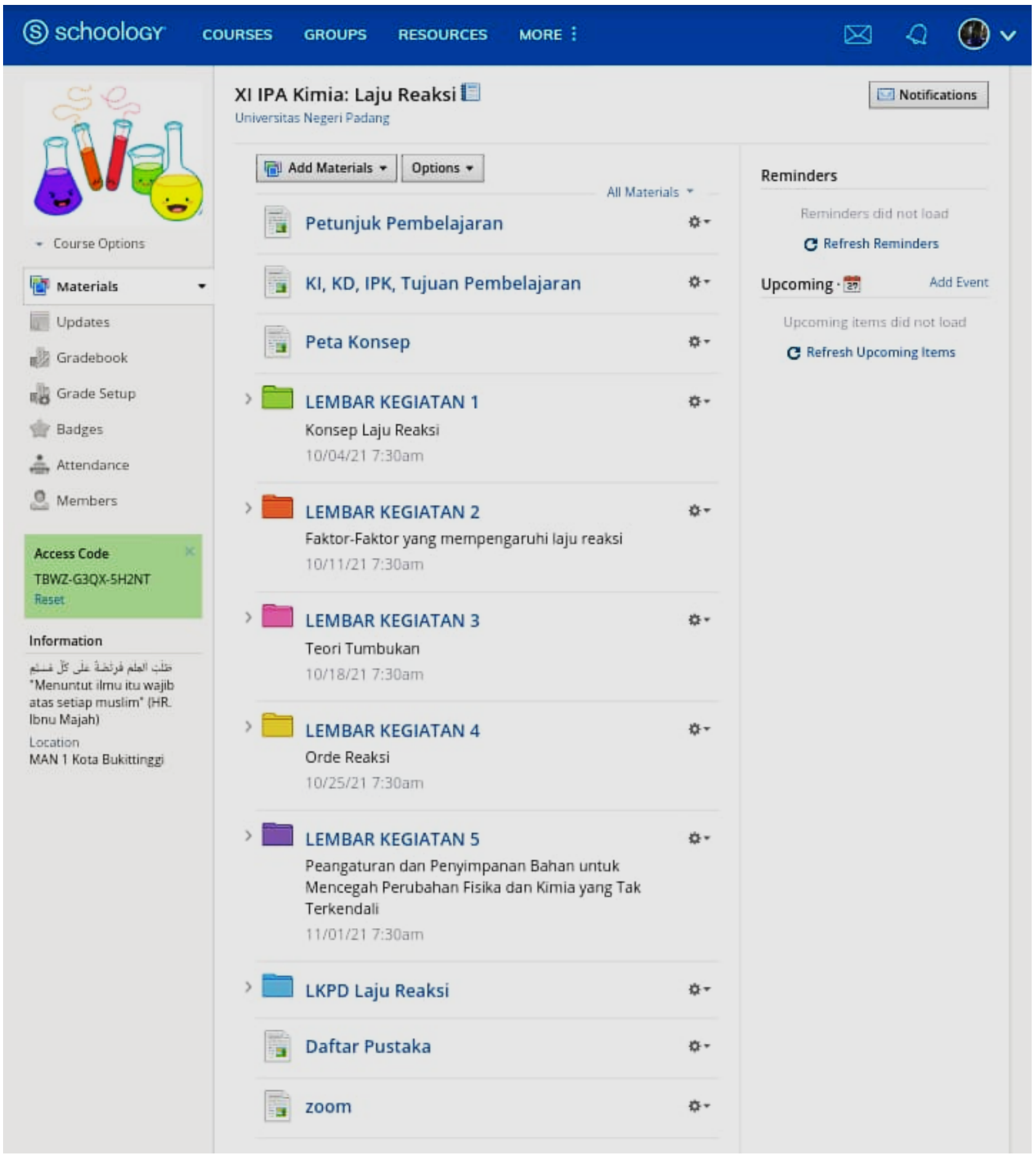

Gambar 2. Tampilan awal courses.

\subsubsection{Tinjauan ahli}

Tinjauan ahli dilakukan dengan uji validitas yang terdiri atas validitas konten, konstruk dan ahli media. Instrumen pengumpulan data uji validitas yang digunakan yaitu berupa angket validitas. Ratarata keseluruhan dari hasil validasi dapat dilihat pada Gambar 3. E-learning menggunakan Schoology berbasis GDL pada materi laju reaksi kelas XI SMA/ MA yang dihasilkan memiliki kevalidan konten 0,92, kevalidan konstruk 0,92, dan kevalidan ahli media 0,92. Jika disesuaikan dengan tabel Aiken, maka dapat dikatakan e-learning menggunakan Schoology berbasis GDL pada materi laju reaksi yang dikembangkan telah valid.

\section{Hasil Uji Validitas Keseluruhan}

Jenis Validasi Indeks Kesepakatan

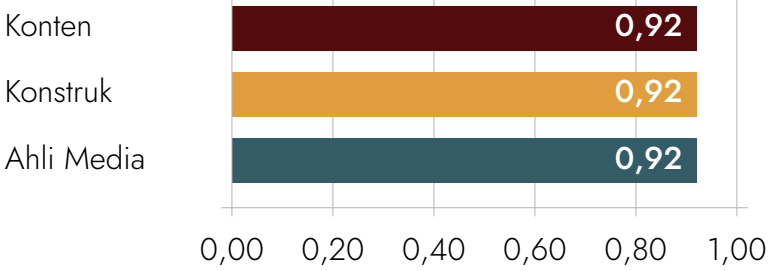

Gambar 3. Hasil Uji Validitas Keseluruhan. 
Hasil validasi konten dari 6 validator untuk setiap lembar kegiatan materi laju reaksi disajikan pada Gambar 4. Validitas konten yang dikembangkan menunjukkan bahwa produk didasari oleh kurikulum yang relevan ${ }^{[29]}$. IPK yang disajikan pada e-learning Schoology telah disesuaikan dengan KD 3.6, 3.7, 4.6, dan 4.7 pada materi laju reaksi, sehingga konten e-learning Schoology pada materi laju reaksi dapat dinyatakan valid.

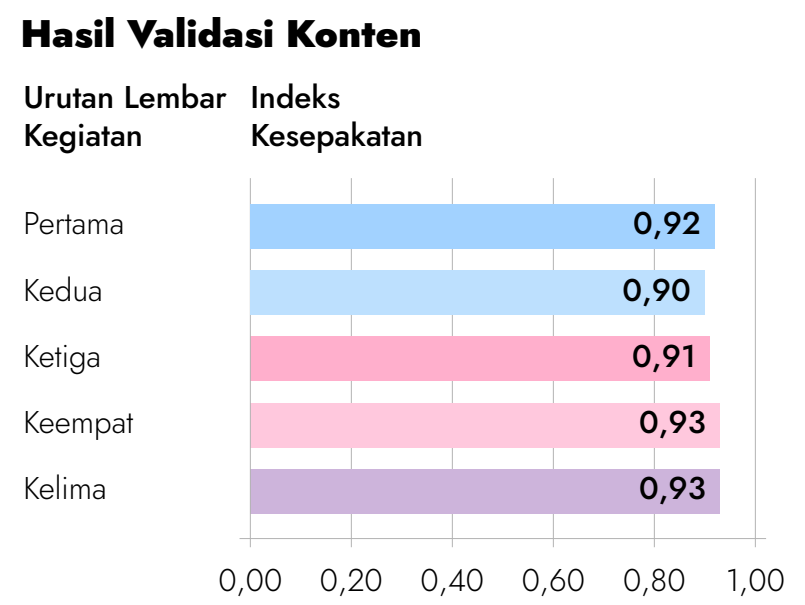

Gambar 4. Hasil Analisis Validasi Konten.

Hasil validasi konstruk dari 6 validator untuk setiap lembar kegiatan materi laju reaksi pada e-learning Schoology berbasis GDL disajikan pada Gambar 5. Validitas konstruk menyatakan konsistensi produk antara komponen satu dengan komponen lainnya ${ }^{[29]}$. Dari diagram pada Gambar 5 dapat dinyatakan bahwa konstruk dari e-learning Schoology dari setiap komponennya sudah valid.

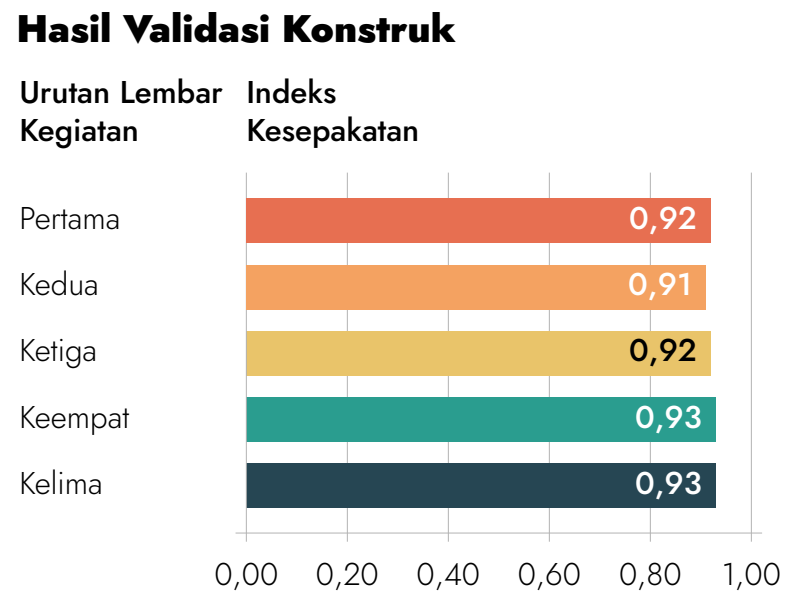

Gambar 5. Hasil Analisis Validasi Konstruk.
Hasil penilaian validasi ahli media didapatkan rata-rata nilai dari setiap aspeknya disajikan pada Gambar 6. Dapat dilihat bahwa kualitas teknis baik itu aspek tampilan, pemograman dan pemanfaatan pada e-learning menggunakan Schoology berbasis GDL pada materi laju reaksi dapat dikatakan valid. Nilai tersebut menunjukkan bahwa pemilihan jenis dan ukuran huruf pada produk sudah tepat, gambar dan video yang disajikan memiliki tampilan yang baik serta desain secara keseluruhan sudah menarik. Desain gambar, video dan animasi yang menarik diperlukan dalam proses pembelajaran yang bertujuan untuk meningkatkan motivasi serta pemahaman peserta didik terhadap materi pembelajaran $^{[30]}$.

\section{Hasil Validasi Ahli Media}

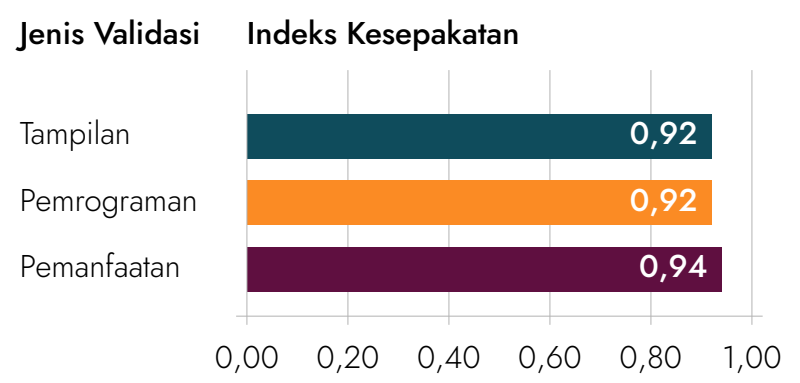

Gambar 6. Hasil Analisis Validasi Ahli Media.

\subsubsection{Evaluasi perorangan}

Evaluasi perorangan (one to one evaluation) dilakukan untuk mengetahui penilaian siswa terhadap media penelitian yang telah dikembangkan dan menindaklanjuti dengan melakukan evaluasi terhadap saran yang diberikan. E-learning menggunakan Schoology berbasis GDL yang dibuatt telah menarik sehingga peserta didik termotivasi dalam mempelajari materi laju reaksi. Jenis huruf, warna, dan ukuran penulisan yang digunakan sudah jelas terbaca. Bahasa yang digunakan pada setiap sintaks GDL sudah menuntun dan dapat mudah dipahami, sehingga membantu dalam menemukan konsep. Video, gambar, animasi yang tersedia sudah menarik sehingga memudahkan dalam memahami materi.

Sintaks-sintaks yang terdapat pada setiap lembar kegiatan dapat membantu peserta didik dalam melatih kemampuan berpikir kritis. Proses pembelajaran dipermudah dengan adanya fitur-fitur yang terdapat pada Schoology. Hal ini juga dibantu dengan adanya petunjuk penggunaan pada LMS Schoology yang telah dikembangkan.

\section{SIMPULAN}

E-learning berbasis Schoology menggunakan model GDL pada materi laju reaksi kelas XI SMA/ MA yang dihasilkan memiliki kevalidan konten 0,92, kevalidan konstruk 0,92, dan kevalidan ahli media 0,92. Sehingga secara keseluruhan e-learning berbasis Schoology menggunakan model GDL pada materi laju reaksi kelas XI SMA/MA yang dikembangkan sudah valid. 
E-learning yang digunakan adalah Schoology jenis basic yang tidak berbayar, sehingga terdapat beberapa fitur yang tidak tersedia. Peneliti menyarankan menggunakan Schoology jenis premium untuk mempermudah sekolah dalam membantu proses pembelajaran. Penelitian dilakukan dengan menggunakan model plomp sampai dengan tahapan prototipe III yakni uji validitas. Diperlukan penelitian lanjutan hingga prototipe IV sampai selesai untuk mengetahui praktikalitas dan efektivitas dari produk yang telah dikembangkan.

\section{REFERENSI}

1. Pratama RE, Mulyati S. Pembelajaran Daring dan Luring pada Masa Pandemi Covid-19. Gagasan Pendidik Indones 2020;1(2):49.

2. Kemendikbud. Panduan Penyelenggaraan Pembelajaran pada Tahun Ajaran dan Tahun Akademik Baru di Masa Pandemi Covid-19: Satuan Pendidikan di Zona Kuning, Oranye dan Merah Dilarang Melakukan Pembelajaran Tatap Muka. Biro Kerja Sama dan Hub Masy Kementeri Pendidik dan Kebud. 2020.

3. Nafrin IA, Hudaidah H. Perkembangan Pendidikan Indonesia di Masa Pandemi Covid-19. Edukatif J Ilmu Pendidik. 2021;3(2):456-62.

4. Rosenberg MJ. E-Learning: Strategies for Delivering Knowledge in the Digital Age. USA: McGraw-Hill. 2001.

5. Samala AD, Fajri BR, Ranuharja F. Desain Dan Implementasi Media Pembelajaran Berbasis Mobile Learning Menggunakan Moodle Mobile App. J Teknol Inf dan Pendidik. 2019;12(2):13-9.

6. Steen HL. Effective eLearning design. J Online Learn Teach 2008;4(4):526-32.

7. Musya'idah, Effendy, Santoso A. POGIL, Analogi Model FAR, KBI, dan Laju Reaksi. Pros. Semin. Nas. Pendidik. IPA. 2016;671-80.

8. Harahap AR, Bayharti. Pengembangan Modul Laju Reaksi Berbasis Guided Discovery Learning untuk Kelas XI SMA/MA. Edukimia. 2021;3(1).

9. Fitrah M, Ruslan. Eksplorasi Sistem Pelaksanaan Evaluasi Pembelajaran di Sekolah pada Masa Pandemi Covid-19. Jurnal Basicedu. 2021;5(1):178-87.

10. Hidayati RE. Effectiveness of Online Learning Using Madrasah E-Learning in the Pandemic Covid-19 Efektivitas Pembelajaran Daring Menggunakan E-Learning Madrasah. J Diklat Keagamaan. 2021;15(1).

11. Ferdianto F, Dwiniasih. Learning Management System (LMS) Schoology: Why it's important and what it looks like. J Phys Conf Ser. 2019;1360(1).

12. Supratman E, Purwaningtias F. Pengembangan Media Pembelajaran E-Learning Berbasis Schoology. J Inform J Pengemb IT 2018;3(3):310-5.
13. Aminoto T, Pathoni H. Penerapan Media E-Learning Berbasis Schoology Untuk Meningkatkan Aktivitas dan Hasil Belajar. J Sainmatika. 2014;8(1):1-17.

14. Surjono HD. Pemanfaatan Teknologi Informasi untuk Pengembangan Bahan Pembelajaran di SMA. Dep Pendidik Nas Direktorat Jenderal Manaj Pendidik Dasar dan Menengah. 2008;1-12.

15. Majid A, Rochman C. Pendekatan Ilmiah Dalam Implementasi Kurikulum 2013. Bandung: PT Remaja Rosdakarya. 2014.

16. Abidin Y. Desain sistem pembelajaran dalam konteks Kurikulum 2013. Bandung: Refika Aditama. 2014.

17. Yerimadesi. Pengembangan Model Guided Discovery Learning (GDL) untuk Meningkatkan Keterampilan Berpikir Kritis Siswa pada Pembelajaran Kimia di SMA. Disertasi Pascasarj Univ Negeri Padang. 2018.

18. P VS. Inquiry Training Model And Guided Discovery Learning For Fostering Critical Thinking And Scientific Attitude. Kozhikode: Vilavath Publications. 2012.

19. Mayer RE. Should There Be a Three-Strikes Rule against Pure Discovery Learning? The Case for Guided Methods of Instruction. Am Psychol. 2004;59(1):14-9.

20. Khasanah VN, Usodo B, Subanti S. Guided discovery learning in geometry learning. J Phys Conf Ser. 2018;983(1).

21. Putri NWMA, Jampel N, Suartama IK. Pengembangan E-Learning Berbasis Schoology Pada Mata Pelajaran Ipa Kelas VIII Di SMP Negeri 1 Seririt. J Edutech Univ Pendidik Ganesha. 2014;2(1):1-11.

22. Huurun'ien KI, Efendi A, Tamrin AG. Efektivitas Penggunaan E-Learning Berbasis Schoology Dengan Menggunakan Model Discovery Learning Terhadap Prestasi Belajar Siswa Pada Mata Pelajaran Sistem Komputer Kelas X Multimedia Smk Negeri 6 Surakarta Pada Tahun Pelajaran 2015/2016. J Ilm Pendidik Tek dan Kejuru. 2017;10(2):36.

23. Plomp. Educational Design Research Educational Design Research. Educ Des Res. Netherlands institute for curriculum development: SLO; 2013;1-206.

24. Plomp T, Nieveen N. An Introduction to Educational Design Research. In: Proceedings of the seminar conducted at the East China Normal University, Shanghai (PR China), November 23-26, 2007. Netherlands institute for curriculum development: SLO; 2007.

25. Aiken LR. Three Coefficients For Analyzing The Reliability And Validity Of Ratings. Educ Psychol Meas. 1985;45:131-41.

26. Kholipah N, Arisanty D, Hastuti KP. Efektivitas Penggunaan E-Learning dalam Pembelajaran Daring Selama Masa Pandemi COVID-19. JPG Jurnal Pendidik Geogr. 2020;7(2):24-33. 
27. Pradana GA, Darsono, Rufaidah E.

Development Of E-learning LKPD Schoology

Improving Critical Thinking Ability and

Learning Outcome Of History. J Stud Sos. 2018;6(1):13-25.

28. Haniah, Asminiwaty N, Sihombing O.

Panduan Pengembangan Pembelajaran

Tata Busana Berbasis Teknologi Digital (Schoology) Untuk Peserta Didik. Kementeri Pendidik Dan Kebud. 2019.

29. Haviz M. Research and Development;

Penelitian Di Bidang Kependidikan Yang Inovatif, Produktif Dan Bermakna. Ta'dib. 2016;16(1).

30. Setiadi T, Zainul R. Pengembangan E-Modul Asam Basa Berbasis Discovery Learning Untuk Kelas XI SMA/MA. EduKimia 2019;1(1):21-7. 